\title{
The Hemopoietic Stem Cell Niche Versus the Microenvironment of the Multiple Myeloma-Tumor Initiating Cell
}

\author{
Dov Zipori
}

Received: 6 December 2009 /Accepted: 29 December 2009/Published online: 5 February 2010

(C) The Author(s) 2010. This article is published with open access at Springerlink.com

\begin{abstract}
Multiple myeloma cells are reminiscent of hemopoietic stem cells in their strict dependence upon the bone marrow microenvironment. However, from all other points of view, multiple myeloma cells differ markedly from stem cells. The cells possess a mature phenotype and secrete antibodies, and have thus made the whole journey to maturity, while maintaining a tumor phenotype. Not much credence was given to the possibility that the bulk of plasma-like multiple myeloma tumor cells is generated from tumor-initiating cells. Although interleukin-6 is a major contributor to the formation of the tumor's microenvironment in multiple myeloma, it is not a major factor within hemopoietic stem cell niches. The bone marrow niche for myeloma cells includes the activity of inflammatory cytokines released through osteoclastogenesis. These permit maintenance of myeloma cells within the bone marrow. In contrast, osteoclastogenesis constitutes a signal that drives hemopoietic stem cells away from their bone marrow niches. The properties of the bone marrow microenvironment, which supports myeloma cell maintenance and proliferation, is therefore markedly different from the characteristics of the hemopoietic stem cell niche. Thus, multiple myeloma presents an example of a hemopoietic tumor microenvironment that does not resemble the corresponding stem cell renewal niche.
\end{abstract}

Keywords Multiple myeloma · Tumor-initiating cells . Hemopoietic stem cells $\cdot$ Stem cell niches $\cdot$ Bone marrow microenvironment

\section{Zipori $(\bowtie)$}

Department of Molecular Cell Biology,

Weizmann Institute of Science,

Rehovot 76100, Israel

e-mail: dov.zipori@weizmann.ac.il

URL: http://www.weizmann.ac.il/mcb/idcards/idzipori.html

\section{Introduction}

Multiple myeloma (MM) is a human malignancy first reported approximately 160 years ago. It apparently initiates by over proliferation of plasma cells, a status called monoclonal gammopathy of undetermined significance (MGUS), that may progress to overt MM in which tumor plasma cells accumulate within the bone marrow microenvironment, causing a bone destructive disease (reviewed by [1-8]). The bone marrow localization of these tumor cells is a most characteristic feature of MM, and it is only at the very late stages of the disease, that the tumor cells may disseminate to other locales. Several drugs, and various other therapeutic modes, such as antibodies to cell surface markers of the tumor cells, are used in the clinic to reduce the disease symptoms (reviewed by [9]. An example is the use of a single-chain $\mathrm{Fv}$ against leukocyte antigen-A that causes myeloma cell death [10]. An effective cure for $\mathrm{MM}$ is still lacking thereby calling for further investigations into the nature of this disease.

The specific bone marrow localization of $\mathrm{MM}$ is reminiscent of the strict dependence of the precursors of plasma cells, i.e., the hemopoietic stem cells (HSCs), upon specific bone marrow niches. This goes along with the cancer stem cell (CSC) theory dealing with heterogeneity among the tumor cell populations (reviewed in [11-36]). It is argued that most cells in the tumor are comparable to mature normal cell counterparts; these "mature" tumor cells are incapable of initiating new tumor formation upon isolation and transplantation into susceptible recipients. By the same token, mature blood cells would be incapable of engraftment and of the establishment of a new bone marrow structure. In contrast, a minor cell population within the tumor, consists of highly proliferating cells capable of tumor formation upon transplantation. These are 
said to be the CSCs based on their rareness, possession of cell surface markers similar to their normal counterpart stem cells and by their superior ability to form tumors. This latter function is regarded as the tumor corollary of the ability of the normal HSCs to create a new hemopoietic tissue in animals or humans deficient in this tissue. The analogy made by many investigators, between tumor formation on the one hand, and normal tissue regeneration on the other, seems somewhat exaggerated: normal tissue generation is accurately programmed and is restricted to embryonic life, while tumor formation is highly chaotic, and may occur throughout the entire life span. These processes, therefore, have little in common. However, in this review, the CSC theory will be taken as is, and the question dealt with below is whether CSCs occur in MM or whether they are absent from this disease.

Several reports show that cellular heterogeneity exists in MM. Only rare cells, within mouse plasmacytoma cell lines, formed tumors upon transplantation [37-41]. Similarly, in vitro analysis of primary MM cells indicated a low incidence of clone forming cells [42]. Thus, the heterogeneous MM population contains some rare clonogenic cells that, at least in vitro, show high proliferation potential. More importantly these cells were capable of recreating the disease in recipient immunodeficient animals [38, 40]. Although the human-to-mouse transplantation model is widely used [43] it is unclear how much it represents a true corollary of the human disease (commented on by [44]). Indeed, human MM has an immune component which is of importance [45], and many cytokines that may have relevance to $\mathrm{MM}$, do not operate effectively across species barriers. From this viewpoint, a 3 dimensional reconstruction of the MM microenvironment ex vivo might prove as informative [46]. The data derived from in vitro and in vivo studies on clonogenic and transplantable MM cells show nevertheless that MM contains a tumor-initiating cell (TIC) component (Box-1). Are these TICs, the MM CSCs? One way to define CSCs is to purify them on the basis of surface marker expression. Such an approach suggested that the putative MM CSCs are $\mathrm{CD} 138^{-} / \mathrm{CD} 20^{+}$ [39]. However, cells capable of transferring the disease were found also in the $\mathrm{CD} 138^{+}$population as well as in the side population (SP) (Commented on by [47]). Whereas the MM TICs were reported to reside within the CD34 population of hemopoietic progenitors [40], other claims relate these cells to the memory B cell population [48, 49]. It is therefore clear, at this point, that marker expression is not a reliable means of identifying CSCs or TICs with any degree of certainty. This is in fact true in the case of all stem cell type (reviewed by $[50,51]$ ). The findings that most plasma tumor cells are capable of forming tumors in immunodeficient mice, when the appropriate conditions are provided $[52,53]$ are more dramatic. According to these findings, the rareness of TICs, which is often compared to the low incidence of normal HSCs found in the bone marrow, is just apparent. A high incidence of tumorforming cells in the cancerous population has been reported [54]. It is probable that TICs seem rare in some assays because of the harsh conditions used that allow only some of the TICs to express their tumor forming potential.

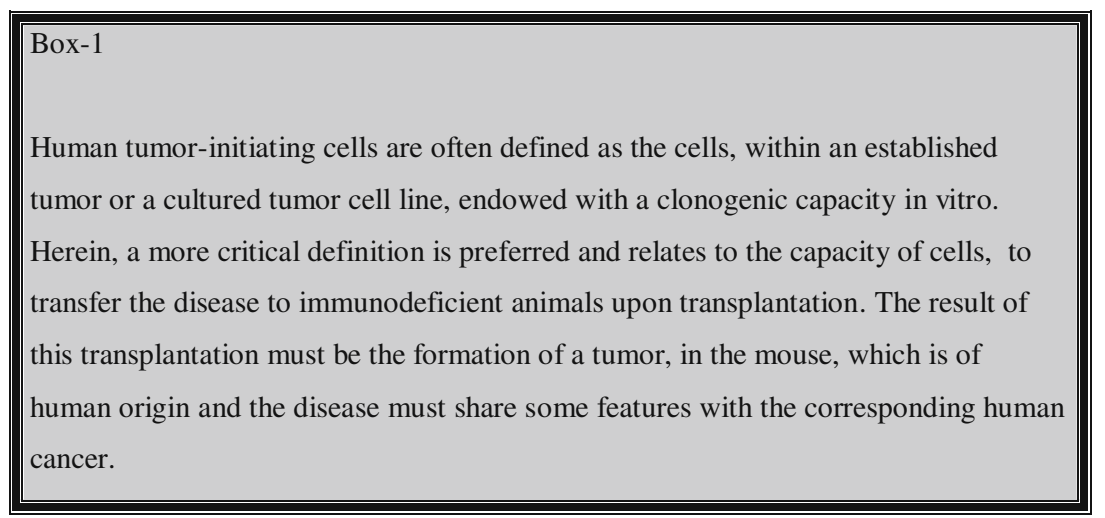

One important point of note is that high proliferation potential is not a HSC property. The latter renew very slowly and their division is a rare event [55]. This constitutes one major difference between HSCs and clonogenic MM cells. Colony formation in culture is mostly a committed hemopoietic progenitor property. Progenitors do proliferate extensively, but transiently. This is in sharp contrast to HSCs that do not proliferate extensively and perform only rare self-renewal divisions. Therefore the in vitro clonogenic cells differ markedly from HSCs and whether they are identical to in vivo TICs or $\mathrm{CSCs}$ is questionable. Although high in vitro proliferation capacity is often regarded as a cancer stem cell property (reviewed by $[48,49,56]$ ), the link between this property 
and the capacity to form tumors is not apparent. The CSC theory is not further analyzed within this review, whereas the similarity/difference between MM TICs versus normal HSCs is examined in detail. The normal HSC in its niche is described first, followed by an analysis of the MM TIC in its bone marrow microenvironment. It is argued that these two cell types and their corresponding microenvironments have little in common.

It is of great importance that a distinction between stem cell niches in particular, and microenvironments in general (Box-2) be made. The microenvironment of an organ contains a wide range of different domains. Some of these are designed to support differentiation, others promote release from the bone marrow compartment and only the highly specialized and rare ones are designed to support stem cell renewal. The latter are designated as the "stem cell niches" (Fig. 1). The function of the stem cell niche is to maintain the stem cell phenotype. The release of the stem cell from the niche will result in differentiation. The terms "niche" and "microenvironment" are often interchangeable in the literature related to stemness. One example is the definition of the niche as an entity essential for survival, growth and differentiation [57]. Clearly, stem cell niches are engaged in antagonism with differentiation rather than with promotion of this process [58-60]. Differentiation inducing domains should therefore not be confused with stem cell maintenance niches. Thus, HSC niches are defined herein as the specific locals within the bone marrow microenvironment, which specialize in maintenance of stem cells in their undifferentiated state.

\section{The Hemopoietic Stem Cell in its Bone Marrow Niche}

Hemopoiesis occurs in the bone marrow, within the bone cavity, wherein the hemopoietic cells and their descendents are engulfed and compartmentalized by a microenvironmental tissue composed of various cell types. This is referred to collectively as the bone marrow stroma. Cells that belong in this category are mesenchymal cells (such as adipocytes and adventitial cells) endothelial cells and some derivatives of the HSC, such as macrophages. The bone marrow stroma is apparently vital for the normal functioning of HSCs. The latter cells depend on the stroma for their renewal and differentiation. It is noteworthy, that most experimental data that demonstrate the functions of stromal cells, have been obtained from in vitro studies. Nonetheless, in vivo observations demonstrated close proximity between hemopoietic cells of immature phenotype and stromal elements, strongly supporting the importance of the stroma in the maintenance and regulation of hemopoiesis.

Although not as solid as epithelial organs, the bone marrow is a well-organized tissue. In the former, cell

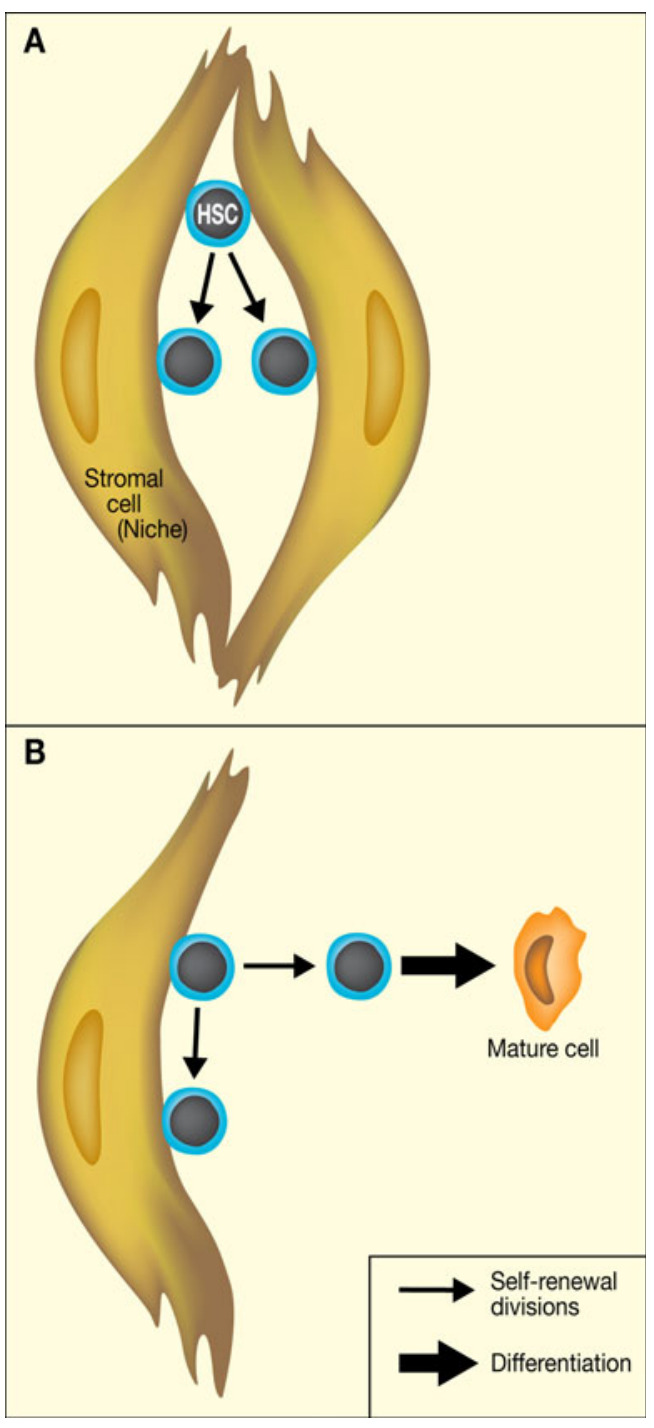

Fig. 1 The general structure of the HSC niche: Self-renewal divisions occurs as long as the stem cell remains within the niche a. Detachment from the niche and departure into other microenvironmental domains result in differentiation $\mathbf{b}$

contacts are enforced by junctional complexes that tightly bind one cell to another. In contrast, within the bone marrow, cells interact through adhesion molecules but are not tightly bound. Hemopoietic cells are capable of intensive motion and migration, within the bone marrow proper, and also migrate back into it from the blood. The bone marrow is nevertheless well organized into distinct compartments, due to the meshwork of stromal cells. The stroma, including the vasculature forms a sponge-like structure attached to the trabecular bone projections, serves both a structural as well as a regulatory function. The localization of stem cells within the bone cavity is not random. It has been shown, by use of histological examination of the bone marrow following depletion, that foci of hemopoiesis first appear at endosteal and periarteolar sites [61]. These 
morphological studies implied that stem cells reside in the specific regions mentioned above, and following injury they start proliferating to supply new mature cells. It was later found that HSCs are specifically localized to the region close to the endosteal bone that was termed the stem cell niche $[62,63]$.

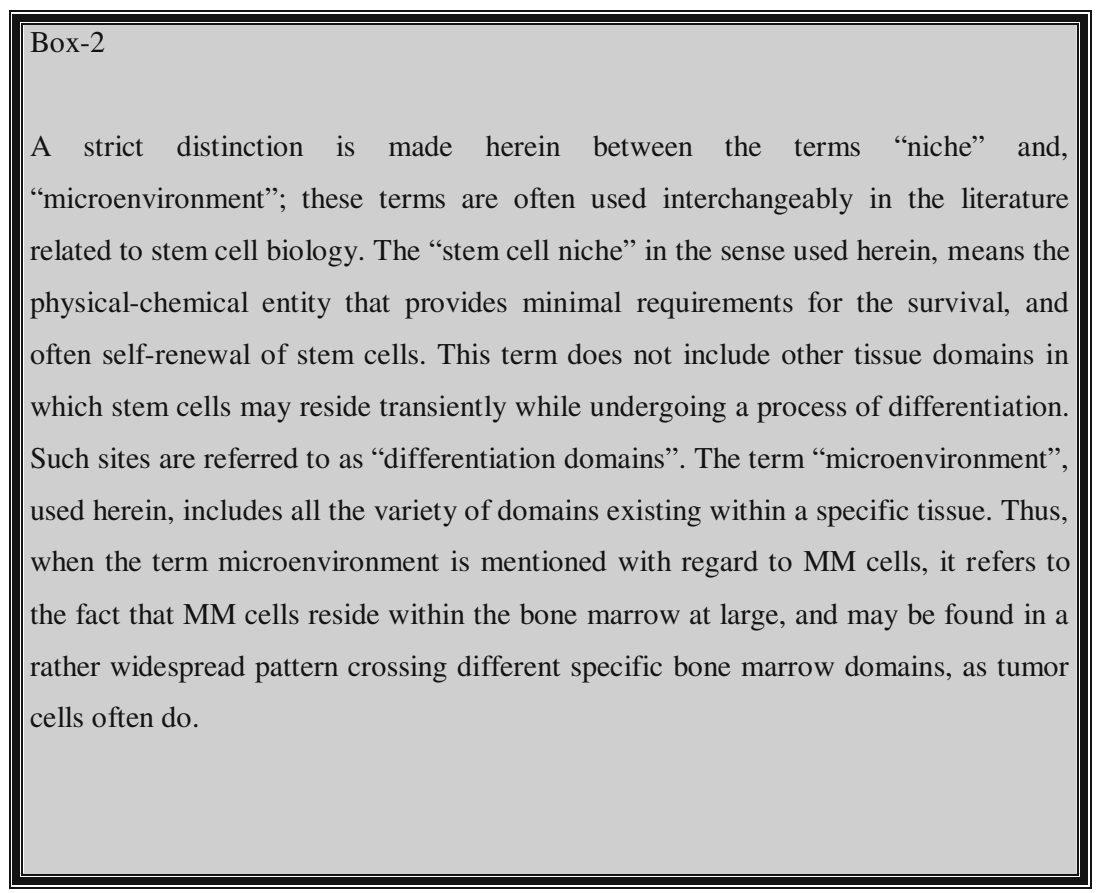

One major constituent of the bone marrow stroma is the mesenchymal tissue. These cells are mostly defined through elimination, in lacking properties of well-defined cells such as hemopoietic, epithelial, neuronal, and endothelial cells. The mesenchyme does not exhibit a specific gene set that may be used practically to identify the cells belonging to this category in vivo. Their identification in culture relies on their adhesion, fibroblast-like morphology and migratory properties. In vitro propagation of mesenchymal cells from bone marrow origin and their re-introduction in vivo demonstrated the capacity of these cells to create a local ectopic stromal structure that induces the homing of HSCs and the subsequent initiation of active hemopoiesis; in vitro seeding of bone marrow cells from guinea pigs resulted in death of the hemopoietic cells and growth of adherent fibroblastoid cells. These cells were suggested to be representatives of the bone marrow microenvironment stromata [64]. The transplantation of these cells, under the kidney capsule of recipient guinea pigs, resulted in the formation of bone structures containing hemopoietic cells. Whereas the bone was found to be of donor fibroblast origin, the hemopoietic cells within the bone structure were of recipient origin [65]. Single cells isolated from fibroblastoid colonies were recently shown to form bone structures in vivo in which hemopoiesis occurred [66]. Co-culture of bone marrow fibroblasts, with freshly isolated hemopoietic cells, results under specific in vitro conditions, in long-term hemopoiesis [67]. Overall, the in vitro culture experiments, taken together with the in vivo findings and morphological observations on the bone marrow structure, suggest that the mesenchymal component of the bone marrow, significantly contributes to the formation of the hemopoietic microenvironment and particularly to the maintenance of the HSC pool. These cells may therefore contribute to the formation of the HSC niche.

The implications of the above studies found support in recent experiments in which the bone marrow niche of HSCs was investigated in vivo. It was found that HSCs reside in the endosteal region in the proximity of osteoblastic cells [68]. HSCs were also found in vascular niches [69]. The niche of normal HSCs seems therefore to be made either of osteoblasts or alternatively endothelial cells, reticular adventitial cells or all of these cells. It is unclear whether the above cell types constitute different entities, or whether they are all derivatives of mesenchymal cells.

A long list of molecules is supposed to contribute, in varying degrees, to the stem cell maintaining capacity of the HSC niche. These include adhesion molecules such as $\mathrm{N}$-candherin [70], very late antigen-4 (VLA-4) [71]) and vascular cell adhesion molecule-1 (VCAM-1) [72]. Hormones and growth factors have been similarly implicated including parathyroid hormone acting through its bone 
marrow receptors [68], osteopontin [73], bone morphogenic protein (BMP) [74], stromal derived factor-1 (SDF-1) and its receptor CXCR4 [75], angiopoietin through its receptor Tie-2 [76], Wnt pathway activation [77], thrombopoietin and its receptor Mpl [78], stem cell factor and its receptor cKit [79], insulin-like growth fctor2 [80], and other factors (reviewed by [81, 82]). The relative contribution of each of the above to niche formation is not completely understood. It is however obvious that stem cell maintenance requires a plethora of signals, rather then a single putative "stem cell renewal factor", which has been pursued for decades.

\section{The Restrictive Nature of Stem Cell Niches}

Notably, several of the factors that emanate from the stem cell niche, listed above as regulators of HSCs, operate in a restrictive manner and do not promote growth. They are often referred to as negative regulators or inhibitors. Earlier attempts to induce in vitro HSC growth, involved a long list of conditions that failed to allow survival of HSCs and their subsequent long-term proliferation. The long-term bone marrow cultures, in which fresh bone marrow is seeded onto pre-formed confluent stromal cell layers, demonstrated the importance and requirement of the stroma for continued hemopoiesis. The combination of stromal cell layers, with hemopoietic colony assays in semisolid medium, allowed the investigation of the events that occur at a single colony forming cell level. The fate of the hemopoietic progenitors in such co-cultures was determined by the stromal cells; hemopoietic colony formation was suppressed by the stroma, and instead of large colonies containing differentiated cells, micro clusters of progenitors emerged. The presence of stroma overrides the effect of cytokines that are needed for colony formation. Separation of the hemopoietic cells from the stroma, by an agar layer, leads to the effect of the stroma being abolished $[58,59]$. Thus, the proximity of the hemopoietic progenitor cell, to the stroma, represses the capacity of cytokines to induce differentiation and, thereby allowing by default, the maintenance of the undifferentiated cells [51]). These experiments suggested, for the first time, that the stroma protects HSCs from differentiation [83] by antagonizing with the function of differentiation-inducing cytokines. The differentiation restraining activity was ascribed to members of the transforming growth factor (TGF) $\beta$ family, which are differentiation antagonists [84, 85] (Fig. 2). The latter family in addition to other molecules, were all proposed to take part in the formation of bone marrow stem cell niches.

The role of differentiation antagonists, in the creation of stem cell niches, has now been well established through studies of Drosophila Melanogaster [60]. Both the gonadal stem cells and the niche cells can be morphologically

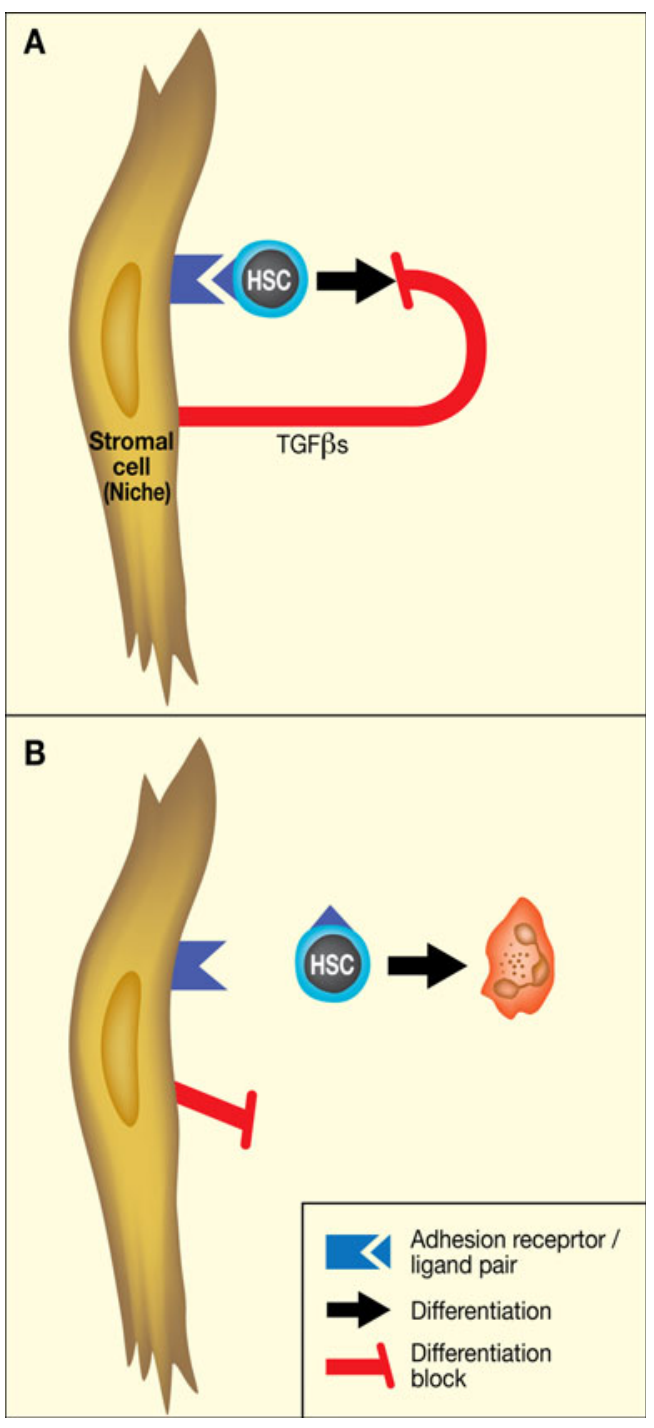

Fig. 2 The mechanism of HSC maintenance within its niche, in an undifferentiated form: Differentiation antagonists such as TGF $\beta$ s, block the capacity of the HSC to respond to differentiation inducing cytokines a. Detachment from the niche releases the stem cell from the effect of the antagonist $\mathbf{b}$

identified in situ. This is completely different from mammalian HSCs, and in fact differs from all other mammalian stem cell systems, which are hard to detect and do not have specific markers that identify them unequivocally. The outstanding advantage of Drosophila stem cells, in being morphologically conspicuous assisted in identifying factors that maintain stem cells in an undifferentiated state within their niche. First and foremost, the direct contact of the stem cell with the niche cell is obligatory. The second requirement is the activity of decapentaplegic (Dpp), the Drosophila homologue of the TGF $\beta$ molecule bone morophogenic protein (BMP). Dpp antagonizes the activity of bag of marbles (BOM), which is a differentiation factor, enabling the maintenance of stem 
cells in an undifferentiated state. The earlier studies on hemopoietic cells and the later on gonadal cells of the fruit fly, taken together, strongly suggest that the stem cell niche provides antagonism with differentiation. This is mediated through molecules such as TGF $\beta$ s, thereby protecting stem cells from overdifferentiation, and directing self-renewal by default.

\section{The Stem Cell Niche and the Stem State}

It thus appears that a niche cell forms a platform for the adhesion of the stem cell. Physical separation from the niche allows the stem cells to react to differentiation factors. In Drosophila, divisions of stem cells that occur while the spindle is perpendicular to the niche, leave one stem cell adherent to the niche. This cell maintains its stemness. The other cell is detached from the niche and starts a differentiation process. However, when such a cell is forced back into the niche, it reassumes a stem cell fate [86] (Fig. 3). Thus, at least in Drosophila, de-differentiation occurs and stem cells may be born out of differentiating cells and not only through self-renewal, as hypothesized for HSCs. Does de-differentiation occur in mammalians? Several publications suggest this option [87-89]. In view of the great similarities between stem cell niches in organisms including plants, Drosophila and mammalians, de-differentiation in mammalians is a realistic possibility which leads to the suggestion that stemness in mammalians, represents a reversible state in the life cycle of the cell [50, 51]. This view is compatible with the ease by which mature cells may be reprogrammed. The reprogramming of skin fibroblasts, liver and gut cells and B lymphocytes, requires the forced expression of 3-4 genes [90-93] whereas the dedifferentiation of neuronal stem cell into induced pluripotent cells requires the overexpression of oct- 4 and Klf4 only [94]. More dramatic is the reprogramming of spermatogonia that occurs spontaneously upon culture without the need for forced expression of exogenously introduced genes [95].

\section{The Bone Marrow Microenvironment of MM Tumor-Initiating Cells}

The bone marrow microenvironment is supportive of cells that apparently do not belong there, such as, metastasizing cells of small lung cell carcinoma, breast carcinoma and prostate tumors. In addition to these remote tumors, the bone marrow microenvironment is a site for the development and maintenance of MM. This bone marrow localization is a fundamental characteristic of MM. Most stages of the disease occur within the bone marrow while

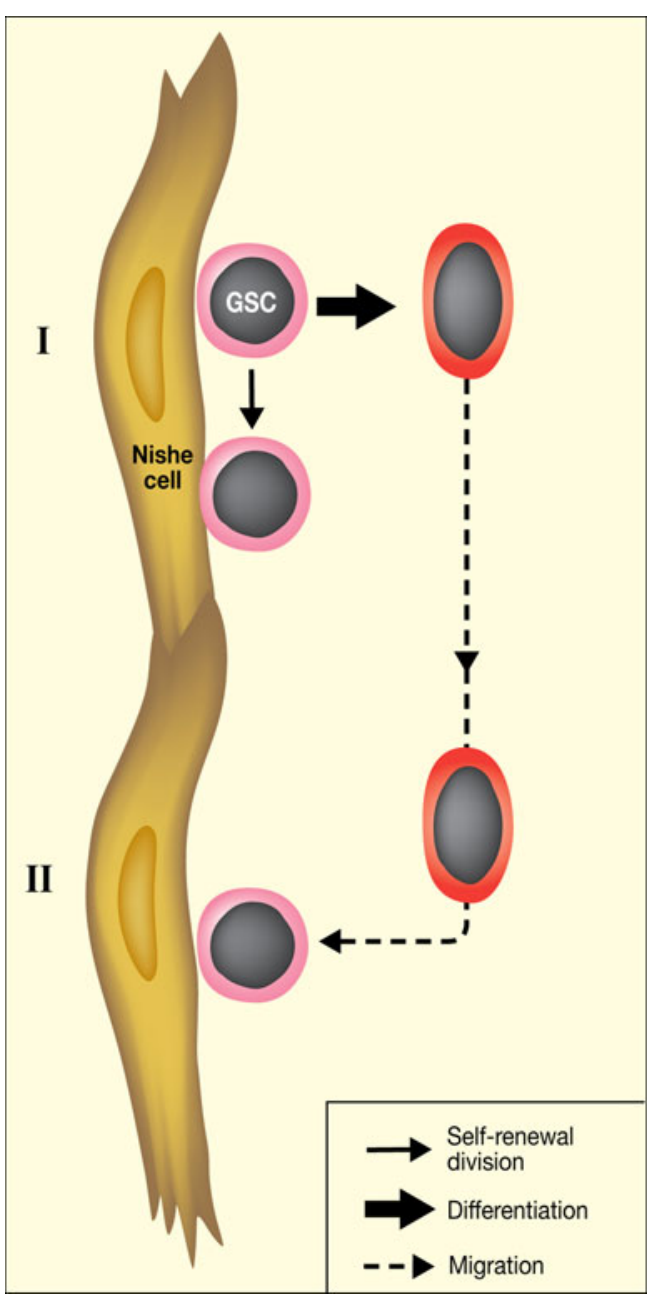

Fig. 3 De-differentiation in Drosophila gonads: The gonadal stem cell (GSC) that remain attached to their niche following division, remain undifferentiated (I) whereas they differentiate upon release from the niche (I). GSC de-differentiate upon return to the niche (II)

dissemination to other tissues and organs is a late occurrence in this disease. It is inferred that the bone marrow microenvironment is required for the development of MM, and that the MM tumor cells, are dependent upon stromal elements of the bone marrow compartment. It has further been suggested that MM cells utilize for their survival and proliferation, molecular cues provided by the bone marrow environment, that are similar to those supporting normal stem cell growth and differentiation. This statement is however hypothetical; it is still not entirely clear what are the molecular cues that the stroma elaborate, which affect hemopoiesis in vivo, both in the case of normal stem cells and in the case of MM cells.

An additional characteristic feature of $\mathrm{MM}$ is the increased osteolytic activity, leading to the high incidence of bone fractures. Bone homeostasis is maintained normally by two opposing activities. Osteoblasts build bone by depositing extracellular-matrix that undergoes mineralization. 
Osteoclasts degrade bone structures by creating a sealing zone into which they release protons and proteases that dissolve the mineral and proteins. The balance between bone formation by osteoblasts and degradation by osteoclasts, results in normal bone remodeling and maintenance of an intact bone structure. It is believed that MM cells cause bone damage by inducing osteoclastogenesis and by diminishing osteogenic functions.

Evidence for the dependence of MM cells upon stromal cells from the bone marrow is mostly indirect. A common way to demonstrate the contribution of a particular cell to a specific function would be cell ablation. Thus, knockout of the T cell receptor (TCR) would result in a lack of mature T cells and is a clear-cut demonstration of the subsequent lack of cellular immunity. A technology for bone marrow stromal cell ablation is unavailable. There are only circumstantial indications for the dependence of MM cells on the bone marrow stroma. Moreover, as will emerge from the following description of experimental systems used to study this issue, most information is based on cell cultures. Several animal models have been constructed for the study of MM. In the mouse, subcutaneous tumors are often used to study the disease. These, however, are rather remote from the human situation. In contrast, the 5T22 tumor model allows for the growth of MM cells within the bone marrow compartment, and therefore this model is the closest to human MM [96]. Immunodefficient mouse models are employed in order to enable the study of human MM cells. One example is the transplantation of human bone into these mice, followed by intra-bone implantation of MM cells [43]. While this model allows the study of human MM cells in vivo, it lacks compatibility in hormonal and cytokine signaling. Furthermore, the model does not include human immune cells, such as T regulatory cells, which are thought to contribute to the pathogenesis of MM.

The general view of MM is that the tumor cells adhere to the bone marrow stroma, and are dependent for their survival and proliferation on growth factors elaborated in the bone marrow microenvironment. Subsequent to their adhesion to the stroma, MM cells induce the secretion of various cytokines, thereby enhancing osteoclastogenesis and damaging osteobalstogenesis. In MM the predominance of the osteoclastic activity brings about bone lesions and fractures, further enhancing the elaboration of cytokines and enhancing MM cell proliferation. These general features of MM are further elaborated on below.

\section{Adhesion of MM Cells to Bone Marrow Stromal Cells}

The adhesion of MM cells to the mesenchymal stroma of the bone marrow has been suggested as being crucial for the proliferation of MM cells. Interference with adhesion processes reduced MM growth, secretion of interleukin (IL)-6 and osteolysis. MM cell lines, co-cultured with a stromal cell line, are often used to study the interactions between MM cells and the stroma. The 5TGM1 mouse myeloma was shown to adhere to the stromal cell line ST2 in one such study. This adherence is mediated by $\alpha 4 \beta 1$ integrin expressed by the myeloma cell line and VCAM-1 found on the surface of the stromal cell [97]. The interaction between the myeloma and stromal cell caused release of bone resorbing activity. The role of $\alpha 4 \beta 1$ integrin was further substantiated in an in vivo study, in which the 5TGM1 myeloma was transplanted into mice, thereby causing osteolysis. This bone damage could be reduced by treatment with antibodies to $\alpha 4$ [98]. An additional integrin, VLA-4, expressed by human primary MM cells or MM cell lines, made a major contribution to the in vitro interaction of these MM cells with fibronectin and VCAM-1 [99] (Fig. 4). The adhesion of MM cell lines, from both humans and mice, was shown to be down regulated by agonists of the peroxisome proliferators-activated receptor (PPAR) $\gamma$ [100]. Adhesion interactions, described in this section, are common to many cellular systems. It is therefore not surprising that some of them are also shared by HSCs.

\section{Drug Resistance Conferred on MM Cells Interacting with Stromal Cells}

Although alkylating drugs and authologous bone marrow transplantation, as well as newly developed drugs such as bortezomib, thalidomide and lenalidomide, improve the health status of MM patients, there is thus far no treatment regimen that results in a complete cure. MM patients often exhibit resistance to drugs and this may in part be due to the adhesive interactions of MM cells with the stroma, which render these cells resistant to the effect of chemotherapeutic agents. The direct adherence of human MM cell lines to primary bone marrow stroma increased their resistance to a

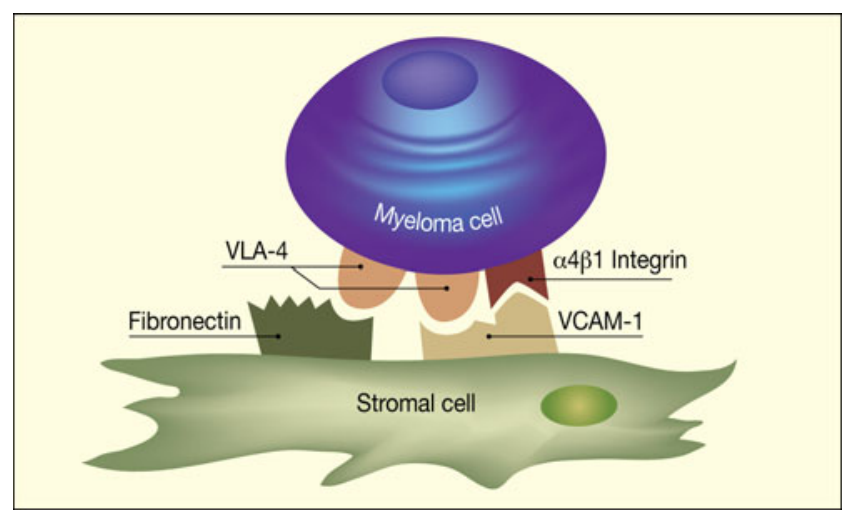

Fig. 4 MM cells adhere to bone marrow stromal cells 
topoisomerase II inhibitor, mitoxantrone. Such resistance could also be conferred by soluble factors released during the interactions between the MM cell line and the stroma [101]. Similar stromal effects mediated by direct interactions and soluble factors conferred resistance of MM cell lines to the apoptosis induced by the Apo2 ligand/TRAIL [102] (Fig. 5) (see below, under "inhibitory cytokines"). The protective effect of the stroma is not general; whereas stromal cells protect a MM cell line from dexamethasone, the same stroma caused increased sensitivity to doxorubicin and melphalan [103]. The resistance granted is due in part to direct cell-to-cell interactions through adhesive interactions but is also conferred by the soluble factors IGF-I and IGF-II [104].

\section{Role of Stimulatory Cytokines in MM}

IL-6, which is one product of bone marrow stromal cells but is expressed by many other cell types, is thought to be a major contributor to MM cell survival and growth in the bone marrow microenvironment. In vitro data show that mouse plasmacytomas are often IL-6 dependent. However, cell lines that are IL- 6 independent, in that they do not require for in vitro growth the addition of the cytokine, are rather prevalent. Some of the latter strive on autocrine secretion of IL-6, while others have a modified, constitutively active, IL-6 signaling cascade. Human MM cells that are otherwise IL-6 dependent, seem to lose this dependence when in contact with bone marrow stromal cells [105]. Toll-like receptor ligands mediate survival of MM cells by inducing autocrine secretion of IL-6 [106]. Human MM cells isolated from the bone marrow are growth stimulated in vitro by IL-6. Their survival is however limited in time. The lack of plasmacytoma development in mice, that are IL-6 deficient, strongly supports the critical role of this molecule in the emergence of this disease [107]. Yet, therapeutic attempts using antibodies to this cytokine have

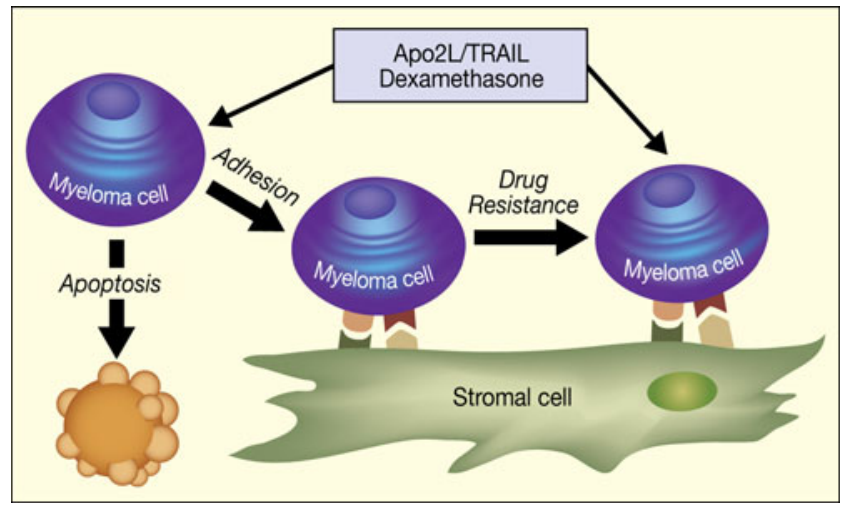

Fig. 5 Adhesion of MM cells to stroma protects the tumor cells from apoptosis not yielded promising results probably due to the multitude of growth factors that could compensate for the absence of IL-6. It is noteworthy that IL-6 has a direct differentiation inducing effect on HSCs and it effectively synergizes with other cytokines to induce massive differentiation. In contrast, it is not known to promote HSC renewal and is not listed amongst the molecules that form the self-renewal niche for HSCs.

Several other cytokines have been implicated as growth factors for MM cells (Fig. 6). These include IL-11, insulin like growth factor (IGF)-1, IL-3 [108], leptin [109], and hedgehog (hh) $[110,111]$. It remains to be determined how each of these molecules contributes to the survival of myeloma cells within the bone marrow compartment. Analysis of intracellular signaling events activated in MM cells, or evoked in them by the growth factors on which they are dependent, indicated a role for several intracellular signaling cascades. These include PI3K, JAK/STAT, Raf and MEK/ERK and NFkB pathways (Fig. 6) (reviewed by [7]). Newly added signaling cascades are the mTORC1 and MTORC2 pathways, which are known to regulate normal cell survival and growth and are activated in many cancers. The molecule DEPTOR suppresses mTORC kinase activity and is therefore expressed at a low level in tumors. By contrast, in a subset of MM, DEPTOR is highly expressed [112]. Similarly to HSCs, the migration of MM cells is influenced by the SDF-1/CXCR4 axis [113].

\section{Role of Inhibitory Cytokines in MM}

Apoptosis is a mode by which cells are killed physiologically in a manner that maintains the intracellular constituents within membranal particles removed by phagocytosis. This ensures that cells are removed from the organism without spilling intracellular molecules that could cause inflammation. Agents that cause apoptosis of MM cells should therefore be considered as possible drugs. Tumor necrosis factors (TNFs) are such death inducing molecules.

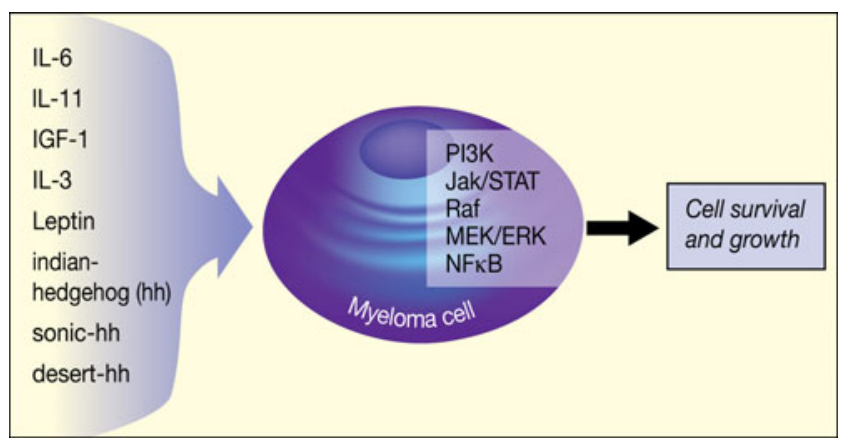

Fig. 6 IL-6 is a major survival and growth factor for MM cells but other cytokines also affect MM cell survival by evoking intracellular signaling cascades 
TNF related apoptosis-inducing ligand (TRAIL), also called Apo2 ligand (Apo2L), interacts with surface receptors to generate a proapoptotic signal through interactions of the receptor intracellular death domains with adaptor proteins that activate proteolytic caspases. TRAIL/Apo2L has been reported to overcome drug resistance of MM cell lines, as well as MM tumor cells obtained from patients [114] (Fig. 5). In addition to its direct effect on MM cells, it has been suggested that TRAIL kills osteoblasts; untreated osteoblasts were resistant to TRAIL, while osteoblast first incubated with MM cells were killed by this molecule [115]. The interactions between MM cells and the stroma, are also affected by decorin, which is a small leucine-rich proteoglycan. Its elimination from the stromal osteoblasts increased the growth of MM cells by inhibiting several pathways that otherwise contribute to myeloma progression (Fig. 7) [116]. Activin A, a member of the TGF $\beta$ superfamily, is expressed by mouse and human bone marrow stromal cells. This molecule has a dual inhibitory effect on MM cells (Fig. 8). Firstly, activin A causes a block in cell cycle progression [117]. Secondly, this molecule is a competitive antagonist of IL-6 [118, 119]. Thus, the molecule kills MM cells that are IL-6 dependent through both mechanisms, and would also affect MM cells that are IL- 6 independent by directly affecting their cell cycle progression.

The stroma is apparently a supportive niche for MM cells. Therefore the finding that a stromal factor, activin A, is capable of mediating MM cell death, is seemingly a contradiction. However, the case may be that in normal bone marrow, the balance between activin A and IL- 6 is in favor of the former, while in MM the titer of IL- 6 is high enough to overcome the inhibitory function of activin A. Indeed, overdoses of IL- 6 overcome the in vitro killing

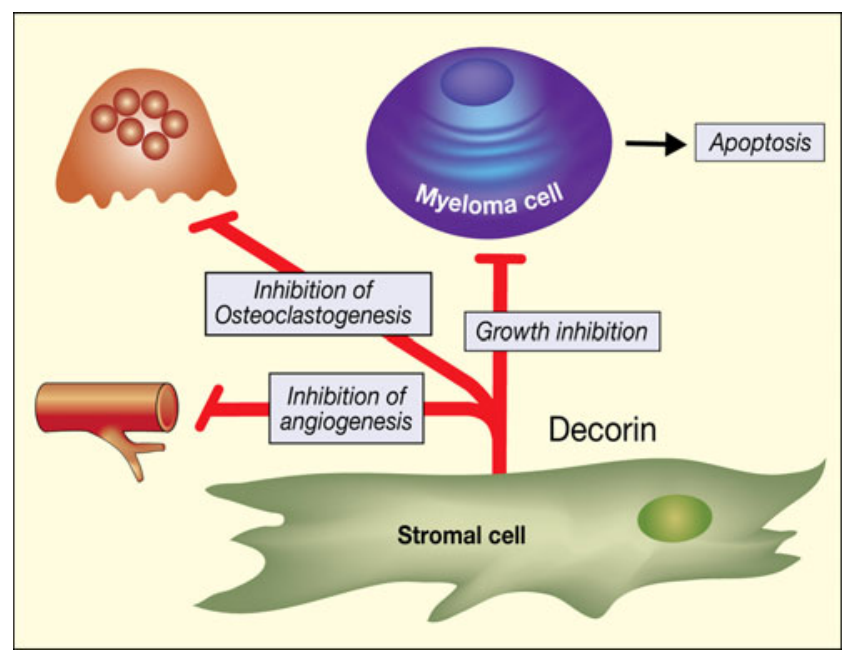

Fig. 7 Decorin, a stroma cell surface proteoglycan elicits several functions that negatively regulate MM cell survival within the bone marrow

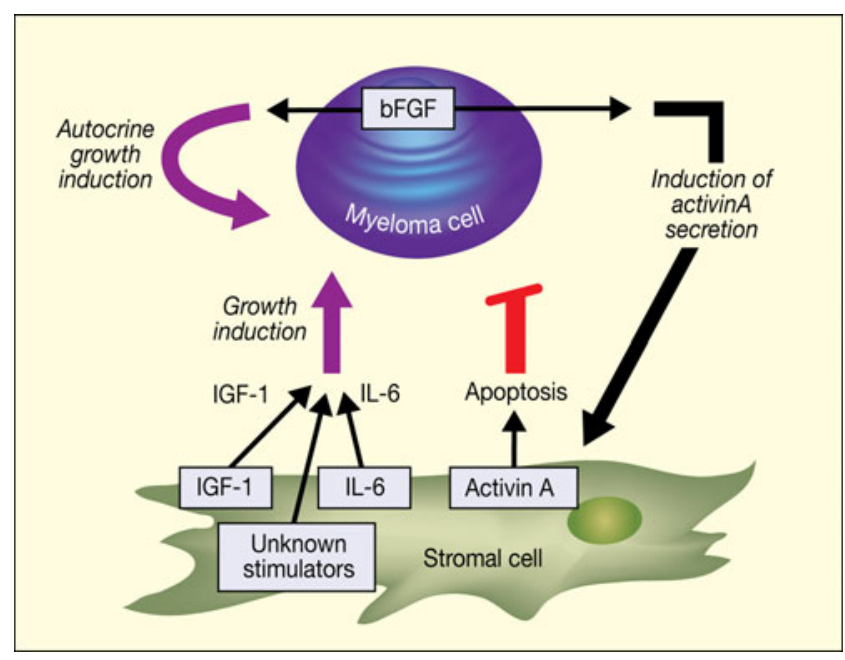

Fig. 8 The stromal cell release the TGF $\beta$ cytokine activin A causes apoptosis of myeloma cells. Additional cytokines that take part in the interactions between the MM cell and the stroma are indicated

effect of activin A [118]. The latter was also demonstrated to inhibit plasmacytoma tumor development in vivo [120].

It is noteworthy that neither of the above listed inhibitors have been implicated as a major player in the HSC selfrenewal process.

\section{Osteoclastogenesis Mediated by MM Cells}

The osteolysis occurring in MM patients is probably due to the presence of MM cells within the bone cavities. MM cells were shown to induce the expression of the receptor activator of NF-kB ligand (RANKL), a major osteoclast activator, in bone marrow stromal cells (Fig. 9) [121, 122]. Moreover, these cells suppress the expression of osteoprotegerin (OPG), a RANKL antagonist. This last finding was recently used in an in vivo disease model. A MM cell line transplanted into $\beta 2 \mathrm{mNOD} / \mathrm{SCID}$ mice developed a bone

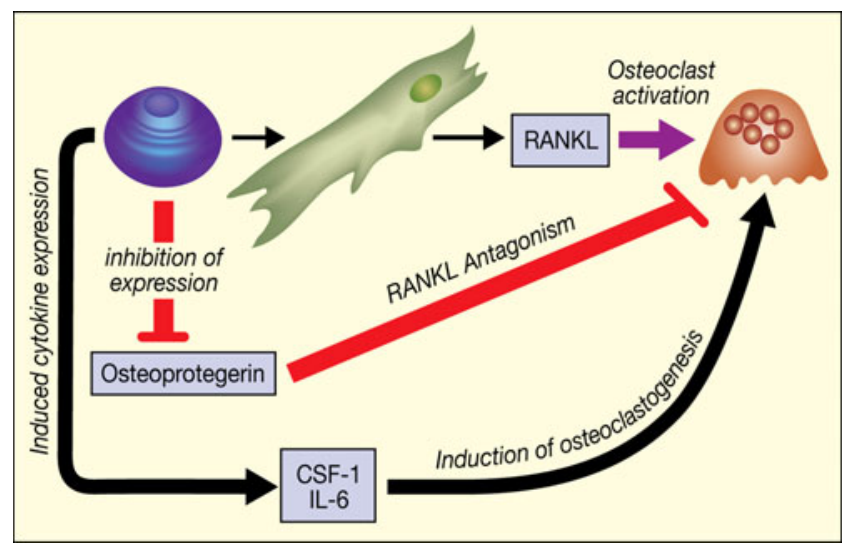

Fig. 9 Several MM cell induced functions lead to osteoclast activation 
marrow disease involving an increase in osteoclast number and bone loss. Upon treatment with multipotent stromal cells, (MSC) transduced with hOPG, bone loss was diminished [123]. MM may thus involve an imbalance between osteoclast stimulation, mediated by RANKL and MIP1 $\alpha$, and inhibitory agents such as OPG and DKK1. In addition, the occupancy of the bone marrow with MM cells causes an accumulation of molecules that potentially augment osteoclastogenesis, including CSF-1, IL-6. Indeed it was found that not only RANKL but also MM cells themselves up-regulate the expression of IL- 6 and IL-11 by bone marrow stromal cells [124]. These findings suggest that in fact the progression of osteolysis would enhance MM growth and dissemination. In line with this conclusion, the treatment of diseased mice with inhibitors of osteoclast activity, reduced bone resorption and also inhibited myeloma growth [125]. One component in the mediation of osteolysis are matrix-degrading proteases. Overall, increased osteoclastogenesis causes bone damage, along side with the secretion of cytokines that promote further myeloma growth and spread (Fig. 10).

\section{Expression and Activity of Proteinases in MM}

A host of proteases have been reported to be expressed in MM. These include the matrix metalloprotease (MMP)-1, MMP-2, MMP-7, MMP-8, MMP-9 and MMP-13, as well as urokinase plasminogen activator (uPA). Several of the MMPs degrade collagen, a major constituent of the bone matrix. uPA cleaves non-collagenous proteins. Therefore, the collective expression of these molecules may contribute to bone lesions in MM. in vitro experiments using both primary myeloma and $\mathrm{MM}$ cell lines cultured with osteoblasts isolated from human bone marrow showed that MM cells induce the expression of MMP-1, MMP-2 and uPA in the osteoblasts [126, 127]. Stromal cells suppress plasma cell IgG production by secreting MMPs that

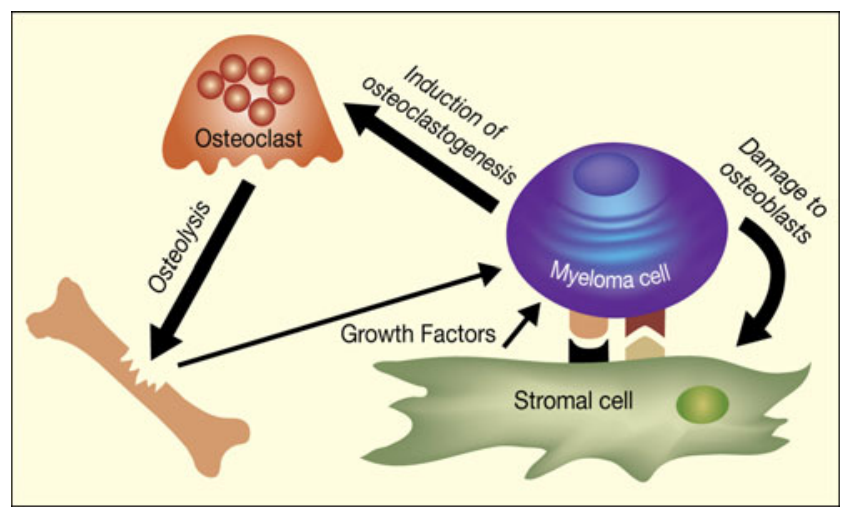

Fig. $10 \mathrm{MM}$ cells induce osteolysis and the release of cytokines that further promote MM cell survival and growth degrade the chemokine ligands CCL2 and CCL7, such that antagonistic degradation products are produced [128].

\section{The Status of the Bone Marrow Mesenchymal Stroma and Osteoblasts in MM}

While osteoclastogenesis is an overt occurrence in MM due to the bone lesions, the possible involvement of osteoblasts in the course of the disease is less pronounced. However, several reports indicate that osteoblasts are targeted in MM. As has been indicated above, cultured MM cells induce the secretion of a variety of cytokines by the mesenchymal stroma and by osteoblastic cells in particular. In addition, protease expression is augmented in the stroma. A number of studies point to a possible damage caused to osteoblasts by MM cells. These experiments imply that the stroma in MM maybe defective. This could be due to the effect of the MM cells themselves. Otherwise, primary defects in the stroma could contribute to the emergence of the disease. The question raised in both cases is whether the bone marrow stroma in MM patients is deficient. Analysis of adhesion molecules expressed by MM stroma, compared to that of normal controls, did not reveal differences. Adhesion of MM cell lines to stroma from patients and normal individuals was shown to be similar [129]. Other studies examined the properties of MSCs. One set of data showed identity in differentiation potential between MM derived and normal MSCs $[130,131]$ whereas another study detected a deficient capacity to osteoblastic differentiation of MM derived MSCs [132]. The latter function was examined by Pevsner-Fischer et al., and was found to be intact in MM MSCs (unpublished observations). This issue is therefore unresolved and further studies are needed. A study using comparative genomic hybridization, indicated that stromal cells from MM patients, show genomic imbalances that were not observed in stroma from normal controls [133]. It remains to be seen whether these occurrences affect MSC biological functions.

\section{Conclusions}

The discussion above highlighted the major features of the HSC niche that maintains the stem cell phenotype. This niche is made of several cellular elements, which are still poorly characterized. Therefore, a clear conclusion as to whether HSCs and MM TIC share the same supportive stromal cell type is premature. It has recently been suggested that macrophages protect MM cells from apoptosis. These cells are an ample source of cytokines and if anything, their presence in the HSC niche would promote differentiation, rather than renewal. More importantly, it 
seems that the macrophages that promote MM survival, are tumor specific cells and may differ from normal macrophages [134]. Thus, the nature of the cells that form the MM microenvironment and those that create the HSC niche is still an open question. However, based on current knowledge the microenvironment of MM tumor seems to markedly differ from that of the normal bone marrow.

In contrast to the vagueness in regards to the exact cell types that form the MM environment versus those that make the HSC niche, it is obvious that HSCs and MM TICs differ markedly in their cytokine requirements. The above summary of cytokines, that affect HSCs self-renewal, highlighted the importance of molecules that antagonize differentiation processes. For example, TGF $\beta$ s reduce differentiation and angiopoietin and thrombopoietin keep HSCs quiescent. Thus, such molecules block the option for differentiation and consequently allow stem cell renewal to occur. The vast majority of MM cells are fully mature plasma-like cells that secrete antibodies. These are end cells in the differentiation cascade and therefore the issue of blockade of differentiation does not apply in MM. It is often argued that most of the MM plasma cells are quiescent and therefore do not contribute to the increase in tumor load. However, TICs are expected to be quiescent and indeed most MM plasma-like cells were found to contribute to tumor formation in a human/mouse model. Certainly, in the mouse, as few as 100 plasmacytoma cells may form a tumor under the skin of Nude mice [120]. The survival of MM cells is dependent on several growth factors, the major one being IL-6. This molecule makes little, if any, contribution to the HSC niche. MM cannot be induced in IL- 6 deficient mice while these mice do not lack HSCs. A major contribution to MM cell survival and growth within the bone marrow compartment is ascribed to osteoclastogenesis, the subsequent osteolysis and release of inflammatory cytokines. The latter promote MM cell survival and growth and allow the spread of the disease within the bone marrow. The complete opposite is true for the HSC. Increased osteoclastogenesis generates signals that drive HSCs away from their niches. It is therefore concluded that there is no solid evidence for any true similarity between HSCs and MM TICs, and these cell types represent distinct biological entities.

One question raised is whether the information available, to date, provides an explanation for the residence of MM cells within the bone marrow. The molecules that have been detailed above as major players in MM, like the adhesion pair VLA-4/VCAM-1 and the cytokine IL-6, are clearly not bone marrow specific. It follows that the specificity in bone marrow localization should be sought in the bone itself. Indeed, osteoclasts are clearly affected by MM, but compelling evidence for the absolute necessity of these cells for the bone marrow localization and retention of MM cells is not available. It would be of importance to examine mice deficient in osteoclasts to clarify this point.

Other candidate cells contributing to the MM TIC microenvironment are the osteoblasts. These cells may be modified in the myelomatous bone compartment, and may therefore serve as a docking site for the malignant cells. However, data available thus far does not support this possibility. It seems that too little effort has been put in the analysis of stromal cells from MM patients. A few studies suggest that MM stroma diverges from normal, while in other studies the MM stroma was found to be normal. Further analysis is needed to resolve this issue.

Acknowledgments The author is indebted to the Helen and Martin Kimmel Institute for Stem Cell Research and the M.D. Moross Institute for Cancer Research, at the Weizmann Institute, the Gabrielle Rich Center for Transplantation Biology and the support of the Legacy Heritage Fund of New York. DZ is an incumbent of the Joe and Celia Weinstein Professorial Chair at the Weizmann Institute of Science.

Open Access This article is distributed under the terms of the Creative Commons Attribution Noncommercial License which permits any noncommercial use, distribution, and reproduction in any medium, provided the original author(s) and source are credited.

\section{References}

1. Hideshima T, Bergsagel PL, Kuehl WM, Anderson KC (2004) Advances in biology of multiple myeloma: clinical applications. Blood 104(3):607-618

2. Edwards CM, Zhuang J, Mundy GR (2008) The pathogenesis of the bone disease of multiple myeloma. Bone 42(6):1007-1013

3. Pagnucco G, Cardinale G, Gervasi F (2004) Targeting multiple myeloma cells and their bone marrow microenvironment. Ann NY Acad Sci 1028:390-399

4. Ribatti D, Nico B, Vacca A (2006) Importance of the bone marrow microenvironment in inducing the angiogenic response in multiple myeloma. Oncogene 25(31):4257-4266

5. Kyle RA, Rajkumar SV (2008) Multiple myeloma. Blood 111 (6):2962-2972

6. Podar K, Chauhan D, Anderson KC (2009) Bone marrow microenvironment and the identification of new targets for myeloma therapy. Leukemia 23(1):10-24

7. Hideshima T, Mitsiades C, Tonon G, Richardson PG, Anderson KC (2007) Understanding multiple myeloma pathogenesis in the bone marrow to identify new therapeutic targets. Nat Rev Cancer 7(8):585-598

8. Mitsiades CS, Mitsiades NS, Richardson PG, Munshi NC, Anderson KC (2007) Multiple myeloma: a prototypic disease model for the characterization and therapeutic targeting of interactions between tumor cells and their local microenvironment. J Cell Biochem 101(4):950-968

9. Ocio EM, Mateos MV, Maiso P, Pandiella A, San-Miguel JF (2008) New drugs in multiple myeloma: mechanisms of action and phase I/II clinical findings. Lancet Oncol 9(12):1157-1165

10. Sekimoto E, Ozaki S, Ohshima T, Shibata H, Hashimoto T, Abe $M$ et al (2007) A single-chain Fv diabody against human leukocyte antigen-A molecules specifically induces myeloma cell death in the bone marrow environment. Cancer Res 67 (3):1184-1192 
11. Normile D (2002) proliferation. Common control for cancer, stem cells. Science 298(5600):1869

12. Dick JE (2003) Breast cancer stem cells revealed. Proc Natl Acad Sci USA 100(7):3547-3549

13. Owens DM, Watt FM (2003) Contribution of stem cells and differentiated cells to epidermal tumours. Nat Rev Cancer 3 (6):444-451

14. Marx J (2003) Cancer research. Mutant stem cells may seed cancer. Science 301(5638):1308-1310

15. Singh SK, Clarke ID, Hide T, Dirks PB (2004) Cancer stem cells in nervous system tumors. Oncogene 23(43):7267-7273

16. Couzin J (2004) Cancer research. Proposed leukemia stem cell encounters a blast of scrutiny. Science 305(5686):929

17. Huntly BJ, Gilliland DG (2004) Blasts from the past: new lessons in stem cell biology from chronic myelogenous leukemia. Cancer Cell 6(3):199-201

18. Bell DR, Van Zant G (2004) Stem cells, aging, and cancer: inevitabilities and outcomes. Oncogene 23(43):7290-7296

19. Jamieson CH, Weissman IL, Passegue E (2004) Chronic versus acute myelogenous leukemia: a question of self-renewal. Cancer Cell 6(6):531-533

20. Scadden DT (2004) Cancer stem cells refined. Nat Immunol 5 (7):701-703

21. Daley GQ (2004) Chronic myeloid leukemia: proving ground for cancer stem cells. Cell 119(3):314-316

22. Trounson A (2004) Stem cells, plasticity and canceruncomfortable bed fellows. Development 131(12):2763-2768

23. Beachy PA, Karhadkar SS, Berman DM (2004) Tissue repair and stem cell renewal in carcinogenesis. Nature 432(7015):324-331

24. Radtke F, Clevers H (2005) Self-renewal and cancer of the gut: two sides of a coin. Science 307(5717):1904-1909

25. Reya T, Clevers H (2005) Wnt signalling in stem cells and cancer. Nature 434(7035):843-850

26. Fomchenko EI, Holland EC (2005) Stem cells and brain cancer. Exp Cell Res 306(2):323-329

27. Clevers H (2005) Stem cells, asymmetric division and cancer. Nat Genet 37(10):1027-1028

28. Huntly BJ, Gilliland DG (2005) Leukaemia stem cells and the evolution of cancer-stem-cell research. Nat Rev Cancer 5 (4):311-321

29. Bissell MJ, Labarge MA (2005) Context, tissue plasticity, and cancer: are tumor stem cells also regulated by the microenvironment? Cancer Cell 7(1):17-23

30. Weissman I (2005) Stem cell research: paths to cancer therapies and regenerative medicine. Jama 294(11):1359-1366

31. Dean M, Fojo T, Bates S (2005) Tumour stem cells and drug resistance. Nat Rev Cancer 5(4):275-284

32. Elrick LJ, Jorgensen HG, Mountford JC, Holyoake TL (2005) Punish the parent not the progeny. Blood 105(5):1862-1866

33. Tan BT, Park CY, Ailles LE, Weissman IL (2006) The cancer stem cell hypothesis: a work in progress. Lab Invest 86 (12):1203-1207

34. Jordan CT (2006) Searching for leukemia stem cells - not yet the end of the road? Cancer Cell 10(4):253-254

35. Vescovi AL, Galli R, Reynolds BA (2006) Brain tumour stem cells. Nat Rev Cancer 6(6):425-436

36. Dick JE (2008) Stem cell concepts renew cancer research. Blood 112(13):4793-4807

37. Bergsagel DE, Valeriote FA (1968) Growth characteristics of a mouse plasma cell tumor. Cancer Res 28(11):2187-2196

38. Matsui W, Huff CA, Wang Q, Malehorn MT, Barber J, Tanhehco $\mathrm{Y}$ et al (2004) Characterization of clonogenic multiple myeloma cells. Blood 103(6):2332-2336

39. Matsui W, Wang Q, Barber JP, Brennan S, Smith BD, Borrello I et al (2008) Clonogenic multiple myeloma progenitors, stem cell properties, and drug resistance. Cancer Res 68(1):190-197
40. Pilarski LM, Belch AR (2002) Clonotypic myeloma cells able to xenograft myeloma to nonobese diabetic severe combined immunodeficient mice copurify with CD34 (+) hematopoietic progenitors. Clin Cancer Res 8(10):3198-3204

41. Pilarski LM, Hipperson G, Seeberger K, Pruski E, Coupland RW, Belch AR (2000) Myeloma progenitors in the blood of patients with aggressive or minimal disease: engraftment and self-renewal of primary human myeloma in the bone marrow of NOD SCID mice. Blood 95(3):1056-1065

42. Karp JE, Burke PJ, Saylor PL, Humphrey RL (1984) Correlation of proliferative and clonogenic tumor cells in multiple myeloma. Cancer Res 44(9):4197-4200

43. Tassone P, Neri P, Carrasco DR, Burger R, Goldmacher VS, Fram R et al (2005) A clinically relevant SCID-hu in vivo model of human multiple myeloma. Blood 106(2):713-716

44. Ferrone S, Sconocchia G (2005) A clinically relevant mouse model of human multiple myeloma? Blood 106:388-389

45. Laronne-Bar-On A, Zipori D, Haran-Ghera N (2008) Increased regulatory versus effector $\mathrm{T}$ cell development is associated with thymus atrophy in mouse models of multiple myeloma. J Immunol 181(5):3714-3724

46. Kirshner J, Thulien KJ, Martin LD, Debes Marun C, Reiman T, Belch AR et al (2008) A unique three-dimensional model for evaluating the impact of therapy on multiple myeloma. Blood 112 (7):2935-2945

47. Katz BZ (2008) Side populations - following the footprints of the elusive multiple myeloma stem cells? Leuk Lymphoma 49 (9): 1657-1658

48. Brennan SK, Matsui W (2009) Cancer stem cells: controversies in multiple myeloma. $J$ Mol Med Sep 17

49. Ghosh N, Matsui W (2009) Cancer stem cells in multiple myeloma. Cancer Lett 277(1):1-7

50. Zipori D (2004) The nature of stem cells: state rather than entity. Nat Rev Genet 5(11):873-878

51. Zipori D (2009) Biology of stem cells and the molecular basis of the stem state. In: Turksen K (ed) Stem cell biology and regenerative medicine. Series. Humana Press, Springer

52. Yaccoby S, Barlogie B, Epstein J (1998) Primary myeloma cells growing in SCID-hu mice: a model for studying the biology and treatment of myeloma and its manifestations. Blood 92(8):2908-2913

53. Yaccoby S, Epstein J (1999) The proliferative potential of myeloma plasma cells manifest in the SCID-hu host. Blood 94 (10):3576-3582

54. Kelly PN, Dakic A, Adams JM, Nutt SL, Strasser A (2007) Tumor growth need not be driven by rare cancer stem cells. Science 317(5836):337

55. Wilson A, Laurenti E, Oser G, van der Wath RC, Blanco-Bose W, Jaworski M et al (2008) Hematopoietic stem cells reversibly switch from dormancy to self-renewal during homeostasis and repair. Cell 135(6):1118-1129

56. Huff CA, Matsui W (2008) Multiple myeloma cancer stem cells. J Clin Oncol 26(17):2895-2900

57. Basak GW, Srivastava AS, Malhotra R, Carrier E (2009) Multiple myeloma bone marrow niche. Curr Pharm Biotechnol 10(3):345-346

58. Zipori D (1981) Cell interactions in the bone marrow microenvironment: role of endogenous colony-stimulating activity. J Supramol Struct Cell Biochem 17(4):347-357

59. Zipori D, Sasson T (1980) Adherent cells from mouse bone marrow inhibit the formation of colony stimulating factor (CSF) induced myeloid colonies. Exp Hematol 8(6):816-817

60. Xie T, Spradling AC (1998) Decapentaplegic is essential for the maintenance and division of germline stem cells in the Drosophila ovary. Cell 94(2):251-260

61. Lambertsen RH, Weiss L (1984) A model of intramedullary hematopoietic microenvironments based on stereologic study of the distribution of endocloned marrow colonies. Blood 63(2):287-297 
62. Lord BI, Testa NG, Hendry JH (1975) The relative spatial distributions of CFUs and CFUc in the normal mouse femur. Blood 46(1):65-72

63. Schofield R (1978) The relationship between the spleen colonyforming cell and the haemopoietic stem cell. Blood Cells 4(1-2):7-25

64. Friedenstein AJ, Chailakhjan RK, Lalykina KS (1970) The development of fibroblast colonies in monolayer cultures of guinea-pig bone marrow and spleen cells. Cell Tissue Kinet 3 (4):393-403

65. Friedenstein AJ, Chailakhyan RK, Latsinik NV, Panasyuk AF, Keiliss-Borok IV (1974) Stromal cells responsible for transferring the microenvironment of the hemopoietic tissues. Cloning in vitro and retransplantation in vivo. Transplantation 17(4):331-340

66. Sacchetti B, Funari A, Michienzi S, Di Cesare S, Piersanti S, Saggio I et al (2007) Self-renewing osteoprogenitors in bone marrow sinusoids can organize a hematopoietic microenvironment. Cell 131 (2):324-336

67. Dexter TM, Allen TD, Lajtha LG (1977) Conditions controlling the proliferation of haemopoietic stem cells in vitro. J Cell Physiol 91(3):335-344

68. Calvi LM, Adams GB, Weibrecht KW, Weber JM, Olson DP, Knight MC et al (2003) Osteoblastic cells regulate the haematopoietic stem cell niche. Nature 425(6960):841-846

69. Kiel MJ, Yilmaz OH, Iwashita T, Terhorst C, Morrison SJ (2005) SLAM family receptors distinguish hematopoietic stem and progenitor cells and reveal endothelial niches for stem cells. Cell 121(7):1109-1121

70. Zhang J, Niu C, Ye L, Huang H, He X, Tong WG et al (2003) Identification of the haematopoietic stem cell niche and control of the niche size. Nature 425(6960):836-841

71. Williams DA, Rios M, Stephens C, Patel VP (1991) Fibronectin and VLA-4 in haematopoietic stem cell-microenvironment interactions. Nature 352(6334):438-441

72. Avecilla ST, Hattori K, Heissig B, Tejada R, Liao F, Shido K et al (2004) Chemokine-mediated interaction of hematopoietic progenitors with the bone marrow vascular niche is required for thrombopoiesis. Nat Med 10(1):64-71

73. Stier S, Ko Y, Forkert R, Lutz C, Neuhaus T, Grunewald E et al (2005) Osteopontin is a hematopoietic stem cell niche component that negatively regulates stem cell pool size. J Exp Med 201 (11): 1781-1791

74. Bhatia M, Bonnet D, Wu D, Murdoch B, Wrana J, Gallacher $\mathrm{L}$ et al (1999) Bone morphogenetic proteins regulate the developmental program of human hematopoietic stem cells. J Exp Med 189(7):1139-1148

75. Peled A, Kollet O, Ponomaryov T, Petit I, Franitza S, Grabovsky $\mathrm{V}$ et al $(2000)$ The chemokine SDF-1 activates the integrins LFA1, VLA-4, and VLA-5 on immature human CD34(+) cells: role in transendothelial/stromal migration and engraftment of NOD/ SCID mice. Blood 95(11):3289-3296

76. Arai F, Hirao A, Ohmura M, Sato H, Matsuoka S, Takubo K et al (2004) Tie2/angiopoietin-1 signaling regulates hematopoietic stem cell quiescence in the bone marrow niche. Cell 118 (2):149-161

77. Fleming HE, Janzen V (2008) Lo Celso C, Guo J, Leahy KM, Kronenberg HM, et al. Wnt signaling in the niche enforces hematopoietic stem cell quiescence and is necessary to preserve self-renewal in vivo. Cell Stem Cell 2(3):274-283

78. Yoshihara H, Arai F, Hosokawa K, Hagiwara T, Takubo K, Nakamura $Y$ et al (2007) Thrombopoietin/MPL signaling regulates hematopoietic stem cell quiescence and interaction with the osteoblastic niche. Cell Stem Cell 1(6):685-697

79. Toksoz D, Zsebo KM, Smith KA, Hu S, Brankow D, Suggs SV et al (1992) Support of human hematopoiesis in long-term bone marrow cultures by murine stromal cells selectively expressing the membrane-bound and secreted forms of the human homolog of the steel gene product, stem cell factor. Proc Natl Acad Sci USA 89(16):7350-7354

80. Zhang CC, Lodish HF (2004) Insulin-like growth factor 2 expressed in a novel fetal liver cell population is a growth factor for hematopoietic stem cells. Blood 103(7):2513-2521

81. Lane SW, Scadden DT, Gilliland DG (2009) The leukemic stem cell niche: current concepts and therapeutic opportunities. Blood 114(6): 1150-1157

82. Iwasaki H, Suda T (2009) Cancer stem cells and their niche. Cancer Sci 100(7):1166-1172

83. Zipori D (1992) The renewal and differentiation of hemopoietic stem cells. Faseb J 6(9):2691-2697

84. Zipori D (1990) Regulation of hemopoiesis by cytokines that restrict options for growth and differentiation. Cancer Cells 2(7):205-211

85. Zipori D, Barda-Saad M (2001) Role of activin A in negative regulation of normal and tumor B lymphocytes. J Leukoc Biol 69(6):867-873

86. Brawley C, Matunis E (2004) Regeneration of male germline stem cells by spermatogonial dedifferentiation in vivo. Science 304(5675):1331-1334

87. Chen X, Mao Z, Liu S, Liu H, Wang X, Wu H, et al (2005) Dedifferentiation of Adult Human Myoblasts Induced by CNTF In Vitro. Mol Biol Cell Apr 20

88. Sharif A, Legendre P, Prevot V, Allet C, Romao L, Studler JM, et al (2006) Transforming growth factor alpha promotes sequential conversion of mature astrocytes into neural progenitors and stem cells. Oncogene Oct 23

89. Matsumoto T, Kano K, Kondo D, Fukuda N, Iribe Y, Tanaka N et al (2008) Mature adipocyte-derived dedifferentiated fat cells exhibit multilineage potential. J Cell Physiol 215(1):210-222

90. Takahashi K, Yamanaka S (2006) Induction of pluripotent stem cells from mouse embryonic and adult fibroblast cultures by defined factors. Cell 126(4):663-676

91. Nakagawa M, Koyanagi M, Tanabe K, Takahashi K, Ichisaka T, Aoi $\mathrm{T}$ et al (2008) Generation of induced pluripotent stem cells without Myc from mouse and human fibroblasts. Nat Biotechnol 26(1):101-106

92. Hanna J, Markoulaki S, Schorderet P, Carey BW, Beard C, Wernig $M$ et al (2008) Direct reprogramming of terminally differentiated mature B lymphocytes to pluripotency. Cell 133(2):250-264

93. Aoi T, Yae K, Nakagawa M, Ichisaka T, Okita K, Takahashi K et al (2008) Generation of pluripotent stem cells from adult mouse liver and stomach cells. Science 321(5889):699-702

94. Silva J, Barrandon O, Nichols J, Kawaguchi J (2008) Theunissen TW. Smith A Promotion of reprogramming to ground state pluripotency by signal inhibition PLoS Biol 6(10):e253

95. Conrad S, Renninger M, Hennenlotter J, Wiesner T, Just L, Bonin $\mathrm{M}$ et al (2008) Generation of pluripotent stem cells from adult human testis. Nature 456(7220):344-349

96. Vanderkerken K, De Raeve H, Goes E, Van Meirvenne S, Radl J, Van Riet I et al (1997) Organ involvement and phenotypic adhesion profile of $5 \mathrm{~T} 2$ and $5 \mathrm{~T} 33$ myeloma cells in the C57BL/ KaLwRij mouse. Br J Cancer 76(4):451-460

97. Michigami T, Shimizu N, Williams PJ, Niewolna M, Dallas SL, Mundy GR et al (2000) Cell-cell contact between marrow stromal cells and myeloma cells via VCAM-1 and alpha(4)beta(1)-integrin enhances production of osteoclast-stimulating activity. Blood 96 (5):1953-1960

98. Mori Y, Shimizu N, Dallas M, Niewolna M, Story B, Williams PJ et al (2004) Anti-alpha4 integrin antibody suppresses the development of multiple myeloma and associated osteoclastic osteolysis. Blood 104(7):2149-2154

99. Sanz-Rodriguez F, Ruiz-Velasco N, Pascual-Salcedo D, Teixido J (1999) Characterization of VLA-4-dependent myeloma cell adhesion to fibronectin and VCAM-1. Br J Haematol 107 (4):825-834 
100. Wang LH, Yang XY, Zhang X, Farrar WL (2007) Inhibition of adhesive interaction between multiple myeloma and bone marrow stromal cells by PPARgamma cross talk with NFkappaB and C/EBP. Blood 110(13):4373-4384

101. Nefedova Y, Landowski TH, Dalton WS (2003) Bone marrow stromal-derived soluble factors and direct cell contact contribute to de novo drug resistance of myeloma cells by distinct mechanisms. Leukemia 17(6):1175-1182

102. Perez LE, Parquet N, Shain K, Nimmanapalli R, Alsina M, Anasetti $C$ et al (2008) Bone marrow stroma confers resistance to Apo2 ligand/TRAIL in multiple myeloma in part by regulating cFLIP. J Immunol 180(3):1545-1555

103. Cheung WC, Van Ness B (2001) The bone marrow stromal microenvironment influences myeloma therapeutic response in vitro. Leukemia 15(2):264-271

104. Xu F, Gardner A, Tu Y, Michl P, Prager D, Lichtenstein A (1997) Multiple myeloma cells are protected against dexamethasoneinduced apoptosis by insulin-like growth factors. Br J Haematol 97(2):429-440

105. Chatterjee M, Honemann D, Lentzsch S, Bommert K, Sers C, Herrmann $P$ et al (2002) In the presence of bone marrow stromal cells human multiple myeloma cells become independent of the IL-6/gp130/STAT3 pathway. Blood 100(9):3311-3318

106. Bohnhorst J, Rasmussen T, Moen SH, Flottum M, Knudsen L, Borset $\mathrm{M}$ et al (2006) Toll-like receptors mediate proliferation and survival of multiple myeloma cells. Leukemia 20(6):1138-1144

107. Hilbert DM, Kopf M, Mock BA, Kohler G, Rudikoff S (1995) Interleukin 6 is essential for in vivo development of B lineage neoplasms. J Exp Med 182(1):243-248

108. Lee JW, Chung HY, Ehrlich LA, Jelinek DF, Callander NS, Roodman GD et al (2004) IL-3 expression by myeloma cells increases both osteoclast formation and growth of myeloma cells. Blood 103(6):2308-2315

109. Caers J, Deleu S, Belaid Z, De Raeve H, Van Valckenborgh E, De Bruyne E et al (2007) Neighboring adipocytes participate in the bone marrow microenvironment of multiple myeloma cells. Leukemia 21(7):1580-1584

110. Dierks C, Grbic J, Zirlik K, Beigi R, Englund NP, Guo GR et al (2007) Essential role of stromally induced hedgehog signaling in B-cell malignancies. Nat Med 13(8):944-951

111. Peacock CD, Wang Q, Gesell GS, Corcoran-Schwartz IM, Jones E, Kim J et al (2007) Hedgehog signaling maintains a tumor stem cell compartment in multiple myeloma. Proc Natl Acad Sci USA 104(10):4048-4053

112. Peterson TR, Laplante M, Thoreen CC, Sancak Y, Kang SA, Kuehl WM et al (2009) DEPTOR is an mTOR inhibitor frequently overexpressed in multiple myeloma cells and required for their survival. Cell 137(5):873-886

113. Gazitt Y, Akay C (2004) Mobilization of myeloma cells involves SDF-1/CXCR4 signaling and downregulation of VLA-4. Stem Cells 22(1):65-73

114. Mitsiades CS, Treon SP, Mitsiades N, Shima Y, Richardson P, Schlossman R et al (2001) TRAIL/Apo2L ligand selectively induces apoptosis and overcomes drug resistance in multiple myeloma: therapeutic applications. Blood 98(3):795-804

115. Tinhofer I, Biedermann R, Krismer M, Crazzolara R, Greil R (2006) A role of TRAIL in killing osteoblasts by myeloma cells. FASEB J 20(6):759-761

116. Li X, Pennisi A, Yaccoby S (2008) Role of decorin in the antimyeloma effects of osteoblasts. Blood 112(1):159-168

117. Zauberman A, Oren M, Zipori D (1997) Involvement of p21(WAF1/ $\mathrm{Cip} 1), \mathrm{CDK} 4$ and $\mathrm{Rb}$ in activin A mediated signaling leading to hepatoma cell growth inhibition. Oncogene 15(14):1705-1711

118. Brosh N, Sternberg D, Honigwachs-Sha'anani J, Lee BC, Shav-Tal Y, Tzehoval E et al (1995) The plasmacytoma growth inhibitor restrictin-P is an antagonist of interleukin 6 and interleukin 11.
Identification as a stroma-derived activin A. J Biol Chem 270 (49):29594-29600

119. Sternberg D, Honigwachs-sha'anani J, Brosh N, Malik Z, Burstein Y, Zipori D (1995) Restrictin-P/stromal activin A, kills its target cells via an apoptotic mechanism. Growth Factors 12(4):277-287

120. Shoham T, Sternberg D, Brosh N, Krupsky M, Barda-Saad M, Zipori D (2001) The promotion of plasmacytoma tumor growth by mesenchymal stroma is antagonized by basic fibroblast growth factor induced activin A. Leukemia 15(7):1102-1110

121. Roux S, Meignin V, Quillard J, Meduri G, Guiochon-Mantel A, Fermand JP et al (2002) RANK (receptor activator of nuclear factor-kappaB) and RANKL expression in multiple myeloma. $\mathrm{Br}$ J Haematol 117(1):86-92

122. Sezer O, Heider U, Zavrski I, Kuhne CA, Hofbauer LC (2003) RANK ligand and osteoprotegerin in myeloma bone disease. Blood 101(6):2094-2098

123. Rabin N, Kyriakou C, Coulton L, Gallagher OM, Buckle C, Benjamin R et al (2007) A new xenograft model of myeloma bone disease demonstrating the efficacy of human mesenchymal stem cells expressing osteoprotegerin by lentiviral gene transfer. Leukemia 21(10):2181-2191

124. Giuliani N, Colla S, Morandi F, Rizzoli V (2004) The RANK/ RANK ligand system is involved in interleukin- 6 and interleukin-11 up-regulation by human myeloma cells in the bone marrow microenvironment. Haematologica 89(9):1118-1123

125. Yaccoby S, Pearse RN, Johnson CL, Barlogie B, Choi Y, Epstein J (2002) Myeloma interacts with the bone marrow microenvironment to induce osteoclastogenesis and is dependent on osteoclast activity. Br J Haematol 116(2):278-290

126. Hecht M, Heider U, Kaiser M, von Metzler I, Sterz J, Sezer O (2007) Osteoblasts promote migration and invasion of myeloma cells through upregulation of matrix metalloproteinases, urokinase plasminogen activator, hepatocyte growth factor and activation of $\mathrm{p} 38$ MAPK. Br J Haematol 138(4):446-458

127. Hecht M, von Metzler I, Sack K, Kaiser M, Sezer O (2008) Interactions of myeloma cells with osteoclasts promote tumour expansion and bone degradation through activation of a complex signalling network and upregulation of cathepsin $\mathrm{K}$, matrix metalloproteinases (MMPs) and urokinase plasminogen activator (uPA). Exp Cell Res 314(5):1082-1093

128. Rafei M, Hsieh J, Fortier S, Li M, Yuan S, Birman E et al (2008) Mesenchymal stromal cell-derived CCL2 suppresses plasma cell immunoglobulin production via STAT3 inactivation and PAX5 induction. Blood 112(13):4991-4998

129. Faid L, Van Riet I, De Waele M, Facon T, Schots R, Lacor P et al (1996) Adhesive interactions between tumour cells and bone marrow stromal elements in human multiple myeloma. Eur J Haematol 57(5):349-358

130. Arnulf B, Lecourt S, Soulier J, Ternaux B, Lacassagne MN, Crinquette A et al (2007) Phenotypic and functional characterization of bone marrow mesenchymal stem cells derived from patients with multiple myeloma. Leukemia 21(1):158-163

131. Giuliani N, Mangoni M, Rizzoli V (2009) Osteogenic differentiation of mesenchymal stem cells in multiple myeloma: identification of potential therapeutic targets. Exp Hematol 37(8):879-886

132. Corre J, Mahtouk K, Attal M, Gadelorge M, Huynh A, FleuryCappellesso S et al (2007) Bone marrow mesenchymal stem cells are abnormal in multiple myeloma. Leukemia 21(5):1079-1088

133. Garayoa M, Garcia JL, Santamaria C, Garcia-Gomez A, Blanco JF, Pandiella A et al (2009) Mesenchymal stem cells from multiple myeloma patients display distinct genomic profile as compared with those from normal donors. Leukemia 23(8):1515-1527

134. Zheng Y, Cai Z, Wang S, Zhang X, Qian J, Hong S, et al (2009) Macrophages are an abundant component of myeloma microenvironment and protect myeloma cells from chemotherapy druginduced apoptosis. Blood 114(17):3625-3628 